\title{
Navigating Through the Maze of Business Process Change Methods
}

\author{
Steven Gross \\ WU Vienna, Austria \\ steven.gross@wu.ac.at
}

\author{
Monika Malinova \\ WU Vienna, Austria \\ monika.malinova@wu.ac.at
}

\author{
Jan Mendling \\ WU Vienna, Austria \\ jan.mendling@wu.ac.at
}

\begin{abstract}
Business Process Management (BPM) is an approach adopted by many organizations for improving their business processes in order to serve their customers more efficiently and effectively. Literature on BPM offers a plethora of methods used as a guide when improving business processes. Some are promoted as methods for process reengineering, while others as methods for improvement, redesign, or innovation. The number of BPM methods is overwhelming, such that organizations are faced with the challenge to select one that best fits their needs. In this paper, we follow a systematic literature review approach to investigate the characteristics of existing BPM methods. We find that the ambition, nature and perspective of the methods are important to determine whether they can be used for radical or incremental process change. Our findings point to the lack of research done on methods for radical process change.
\end{abstract}

\section{Introduction}

Business processes play an important role in the value creation of organizations and are used to satisfy customer needs through the execution of activities [1]. Business Process Management (BPM) is a discipline used to discover, analyze, improve, and control business processes. Organizations often rely on BPM methods to assist the systematic change of their existing or the development of new business process designs [2]. These new process designs can be of an incremental or radical nature [3].

In the last three decades such BPM methods have been introduced, refined, and applied. These methods are often framed as process reengineering, process improvement, or process redesign. Each of these themes originates from a different set of principles and practices, although they are all used to incrementally or radically improve business processes. What is still unknown is whether the different methods indeed offer the same outcome, or they have different characteristics that could be used to accomplish different types of goals. Additionally, it is uncertain in which situations specific methods are applicable and when a specific one should be preferred. Insights are lacking on the differentiating factors of the different methods that would allow us to judge their applicability.

In this paper, we address this research problem by conducting a systematic literature review. More specifically, we identified 98 research articles that introduce a method used to guide organizations during their process change efforts. Our results show that, in contrast to process redesign, process reengineering and improvement methods seem to offer more strategically-oriented activities. Also, the majority of methods have been tailored to lead to incremental process improvement, whereas only few have been used for radically changing processes.

This paper proceeds as follows. In Section 2 we introduce the concept of BPM and elaborate on previous research done on the differently-themed process change methods. Section 3 is where we explain our research method and elaborate on the collection and analysis of data. In Section 4 we present and discuss our findings. We conclude the paper with Section 5, where we provide a brief summary and point to limitations.

\section{Background}

Business process management is an approach followed by organizations for discovering, analyzing, improving and controlling their business processes [1, 4]. A business process is a collection of activities, events, and decisions performed with the aim to satisfy customers' needs. [5, 6]. BPM has developed from ideas of Business Process Reengineering (BPR) [7] towards permanent practice to improve processes in both incremental and radical ways. Incremental process change involves performing the same business process with slightly increased efficiency, whereas radical process change is often organizationally disruptive [3]. 
Table 1. Characteristics of incremental and radical

\begin{tabular}{l|l|l}
\multicolumn{2}{c}{$\begin{array}{c}\text { process change [3] } \\
\text { Incremental }\end{array}$} & Radical \\
\hline Starting point & Existing process & Clean slate \\
Frequency of change & One-time/Continuous & One-time \\
Time required & Short & Long \\
Participation & Bottom-up & Top-down \\
Typical scope & Narrow, within functions & Broad, cross-functional \\
Risk & Moderate & High \\
Primary enabler & Statistical control & Information technology \\
Type of change & Cultural & Cultural/Structural \\
\hline
\end{tabular}

According to [3], incremental and radical process change have differing characteristics. These can be seen in Table 1. Incremental process change involves taking an existing business process done within one department as a starting point, analyzing it in order to find its weaknesses, and improving it accordingly. The time required is often short and such change is typically initiated by the company employees. On the other hand, performing a business process in an entirely new way is a trait that characterizes radical process change. Instead of taking an existing business process, an organization starts with a clean slate. This type of undertaking is done only once, because it often requires a long time, especially because the process that is being changed is cross-functional. The initiative is driven by the newly formulated vision of the company and requires strong commitment from the management. Radical process change often takes advantage of new technologies, and it affects both the organizational culture and structure [3].

A method is a set of principles used to guide users through actions in order to improve a perceived real-world problem situation [8]. Improving business processes is one example of such a real-world problem situation. Thus, organizations that adopt BPM typically deploy methods in order to be able to discover, analyze, and improve their business processes, both incrementally and radically. Since the 1990s a multitude of methods have been proposed for organizations to follow during their process change efforts. These methods include activities that would assist organizations in achieving an overall management of their business processes, while changing a process. In this study, the term process change incorporates all efforts that aim to enhance a business process. However, different terms are often used to refer to process change methods, including reengineering, improvement, optimization, and redesign.

Some of the first methods assisted organizations on how to incrementally and radically reengineer their business processes (e.g. [7]). For instance, [9] presents a case study where a process reengineering method has been used in the banking industry with the aim to simplify the business processes, and to radically change them in order to refocus the organization on its customers. Other studies have shown that process reengineering has been applied in order to achieve breakthrough improvements in performance which would likely reshape the organization [10]. There are also case studies that use process reengineering as means to guide incremental process improvement efforts, such as reducing costs and cycle time, and increasing quality $[11,12,13]$. Often, organizations reengineer their processes to benefit from emerging technologies in order to realize radical organizational transformation [14].

One example of a reengineering method still widely used today is the Stage-Activity (S-A) framework [2]. It includes the six stages of envision, initiate, diagnose, redesign, reconstruct, and evaluate. Each stage is done in a predefined order and involves a number of activities companies should conduct in order to reengineer their business processes. One of the reasons it is still acknowledged today is because it is holistic, thus it includes both strategic (e.g. secure top management support) and operational activities (e.g. document and analyze existing process). The framework has also been derived following an inductive procedure which uses data from both practice and research.

Process improvement is another prevalent theme of existing BPM methods. These offer activities to streamline and automate processes in order to improve the company's efficiency and customer satisfaction [15]. Many process improvement methods often use principles from Total Quality Management (TQM) or Six Sigma (e.g. $[16,17,18])$. TQM focuses on continuous quality improvement, whereas Six Sigma aims in improving the company's performance in terms of time, cost, and quality. Benchmarking seems to be another technique applied by organizations when improving their processes [19]. It involves investigating approaches used by competitors to see what can be learned from them [19]. These new insights are used to improve the company's existing business processes.

Similarly, there exist methods that guide organizations during their process redesign efforts (e.g. [20]). As with reengineering, these have also been used to achieve both incremental and radical process change. According to [21], an incremental process redesign could be achieved in half of the time radical process redesign needs. Some of the process redesign methods specify how to deploy information technologies which enable easier transfer of information across longer distances, allow multiple tasks to be worked in parallel, and make the communication between multiple parties involved in the execution of the same business process easier [22, 23]. Others are followed for achieving 
excellence in business processes and their continuous improvement [20]. A process redesign initiative should deliver a process design that is in some way superior to the existing one [24]. To achieve this, 29 redesign heuristics have been proposed for organizations to follow in order to decrease the time and cost, and increase the quality and flexibility of their business processes [1, 24].

The redesign orbit is an example of a classification schema used to organize the spectrum of process change methods [1]. According to [1], a method can differ in terms of three dimensions. These are, ambition, i.e. the magnitude of the change the method seeks to bring about, nature, i.e. whether the method relies on data or rather creative ideas, and perspective i.e. the perspective being taken by the redesign method [1]. The ambition of a method could be transactional if it improves business processes incrementally, or transformational if it changes a process radically. The nature of a redesign method could be analytical if it uses quantitative techniques to analyze the business processes, or creative if it embraces human creativity to come to new ideas. Lastly, a redesign method could take the inward-looking perspective, which assumes a viewpoint of the organization that undergoes the BPM initiative, or an outward-looking perspective, which takes an outsider's perspective on the process. In [1], process reengineering is considered a rather transformational method, whereas the process redesign heuristics have a slight transactional tendency. Both are considered analytical and inward-looking. On the other hand, benchmarking is a transformational and outward-looking method, however with an analytical nature.

Clearly, there are various process change methods, along with some classification schemes to organize them. What has hardly been addressed in information systems research is the question when and where a certain method is best suited to achieve a certain goal. This is surprising, because it is already well-established in other fields like software engineering, where methods have to be modified to meet specific settings [25]. In the following, we use a systematic literature review to gather existing process change methods in order to investigate their differing characteristics.

\section{Research method}

The objective of this study is to investigate the characteristics of the various process change methods that exist. We follow a systematic literature review approach as proposed by [26] in order to gather all methods that have been reported in past studies and have been used as guidance for both incremental and radical process change. In the following, we explain our data collection and analysis methods.

\subsection{Data Collection}

As a first step, we prepared a review protocol we follow when searching for literature on process change methods. We used the digital library ProQuest to search for papers that introduce and list activities organizations should follow during their BPM initiatives. Our search query included two sets of keywords. The first set comprised of the following keywords: "process re*engineering" OR "process improvement" OR "process innovation" OR "process optimi?ation" OR "process re*design". These are all terms that are often used as synonyms and imply a change in a process. The second set of keywords included the following keywords: method* OR procedure OR technique OR approach OR framework. All of these terms are used to indicate guidance to choose actions in order to intervene with some problem. We used the conjunction AND to connect both. The combination of the two sets of keywords would return as result papers that offer some type of guidance for incrementally or radically improving a process. We targeted peer-reviewed papers written in English that include a combination of the keywords in their title or abstract. We limited our search to scholarly journals and conference papers published until 2018.

As a result of our search we retrieved 1,778 papers. During the next phase of the review, we started to identify the relevant studies by reading the title and abstract of the retrieved papers. To determine the relevancy, the title and abstract should indicate that the respective paper introduces a method which includes specific activities organizations could follow in order to change their business processes. We considered 184 papers to be good candidates for the second round of reviews, which includes reading the entire paper. The identification of primary sources was done by two researchers, independently. Both researchers screened each paper to determine whether it was relevant. Each disagreement on whether a paper should belong to the primary sources was discussed, and a subsequent consensus was reached. As a result, we ended up with 98 primary sources that went through analysis.

\subsection{Data Analysis}

The final step of the literature review was extracting and synthesizing the required data from the 98 primary sources. From each of the 98 papers, we extracted the stages and their according activities that comprise the 
respective method, and recorded the theme. We use as basis the Stage-Activity (S-A) framework for BPR as introduced in [2] to identify all activities organizations have followed during their BPM initiatives. We use this framework as reference because it includes both strategically- and operationally-oriented activities, and it has been derived following an inductive procedure which uses data from both practice and research.

The S-A framework includes six stages, each comprising a number of activities organizations have followed when reengineering their business processes. First, in order to make sure that the activities included in the S-A framework are exhaustive, we analyze the additional 97 methods. Whenever we found an activity which is related to any of the six stages of the S-A framework and is not mentioned in [2] we included it accordingly in the respective S-A framework stage. As a result, we derived a list of unique activities for each of the six stages. Second, we coded the 98 methods on basis of the list of unique activities for each stage. For this, we analyzed each method and indicated if an activity of the respective method also belongs to the list of unique activities. We did this for all 98 methods in a step-wise manner. This enables us to differentiate between the activities included in the methods themed as process improvement, reengineering, innovation, redesign and optimization.

As a next step, we use the coded data in order to categorize the 98 methods in terms of their ambition, nature and, perspective. These are the three dimensions of the redesign orbit as introduced by [1]. For each method, we identified whether it is outward- or inward-looking (perspective), creative or analytical (nature), and transactional or transformational (ambition). An outward-looking method is one which includes activities that recommend to consider the requirements of customers or third parties before changing a business process. Whereas, an inward-looking method is one which considers the company's requirements as the only source for inspiration to change a process. A creative method embraces human creativity and ingenuity [1]. Thus, we categorized a method as creative if it includes activities that recommend the use of brainstorming where people stimulate each other to come up with new ideas on how to organize a business process [1]. Otherwise, a method is analytical if it only analyzes the current state of the company and its business processes following quantitative and qualitative methods.

To asses whether a method is transactional or transformational was not as straightforward. For this, we used the characteristics of incremental i.e. transactional and radical i.e. transformational process change as introduced by [3]. If provided, for each method we identified its starting point, frequency of change, time required, participation, typical scope, risk, primary enabler and type of change (see Table 1). For example, if a method includes an activity which recommends to start the process change by first discovering the existing business process, then it fulfills a characteristic of incremental process change. Otherwise, if an activity recommends to start with a clean slate, this is a characteristic of radical process change. Similarly, if at least one activity in a method recommends to establish the strategic direction and vision of the company prior to changing a process, the method is top-down, which is a characteristic of radical process change. However, if instead the BPM initiative is led by process participants and the BPM team, then it is as a bottom-up method, a characteristic of incremental process change. The other characteristics that define whether a method has a transactional or transformational ambition could also be identified by the activities a method includes. Therefore, we specified for each method which incremental and radical process change characteristics it fulfills. One method could fulfill both incremental and radical characteristics, because a method could be used for incremental as well as for radical process change.

Once we characterized each method, we summed up the number of characteristics each method fulfills in order to find out whether the ambition of the method is more transactional, transformational or both. If the number of radical characteristics exceeded the number of incremental characteristics by at least two, the method was categorized as transformational. Similarly, if the number of incremental characteristics exceeded the number of radical characteristics by at least two, the method was categorized as transactional. If this difference was less than two (one or zero), than the ambition of the method could be both transactional and transformational. As a result, we were able to categorize each method as transactional, transformational or both.

As a last step of our analysis, we position the 98 methods in the spectrum of the redesign orbit by considering whether they are inward- or outward looking, creative or analytical, and transactional or transformational. As a result, we are able to discuss the differences between the 98 process change methods in terms of their ambition, nature, and perspective. Next, we present and discuss our findings.

\section{Results}

In this section we present our findings. First, we provide insights into the differences between 


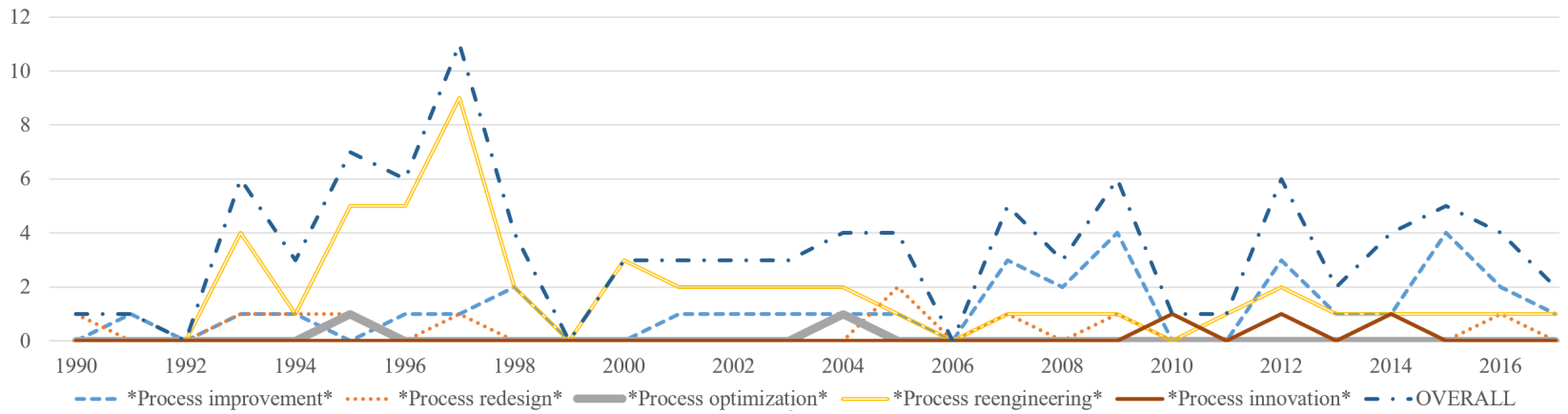

Figure 1. Introduction of methods over time

the different-themed methods. Second, we show a framework with all unique activities included across all methods we found. Third, by means of the redesign orbit we illustrate the position of each method we analyzed, in terms of its nature, perspective and ambition. Last, we discuss our findings.

\subsection{Findings}

From the 98 methods we collected, 49 were themed as process reengineering, 33 as process improvement, 11 as process redesign, 3 as process innovation, and 2 methods had the theme of process optimization. The distribution of the occurrence over time of the different method themes is shown in Figure 1. From Figure 1 we can observe that the first method introduced in 1990 was one organizations could follow for their process redesign initiative. Shortly after followed a process improvement method, whereas process reengineering methods started to occur in 1992, reaching its peak in 1997, with nine published studies that guide organizations on how to reengineer their business processes. Since then, process change methods have been continuously proposed until 2017. Initially, the process reengineering theme was clearly dominating, while the theme of process improvement became more popular within the last 10 years. Only three process innovation methods were found, all introduced between 2010 and 2014. The only two process optimization methods were published in 1994 and 2004.

Table 2. Theme/stage heat map

\begin{tabular}{|c|c|c|c|c|}
\hline & \multicolumn{3}{|c|}{ Theme } \\
\hline & & Redesign & Reengineering & Improvement \\
\hline \multirow{6}{*}{$\begin{array}{l}\text { D. } \\
\text { 焉 }\end{array}$} & Envision & $64 \%$ & $90 \%$ & $85 \%$ \\
\hline & Initiate & $45 \%$ & $55 \%$ & $70 \%$ \\
\hline & Diagnose & $91 \%$ & $86 \%$ & $94 \%$ \\
\hline & Redesign & $100 \%$ & $96 \%$ & $97 \%$ \\
\hline & Reconstruct & $100 \%$ & $86 \%$ & $82 \%$ \\
\hline & Evaluate & $36 \%$ & $67 \%$ & $79 \%$ \\
\hline
\end{tabular}

Based on the mapping of activities from the 98 methods to the stages of the S-A framework from [2] we derive a heat map that illustrates how the three process change themes of reengineering, redesign and improvement differ from each other. We excluded the process optimization and innovation methods because the sample was too small to be used for comparison. Table 2 shows, for each of the three themes of process change, how many of the different-themed methods offer at least one activity in the corresponding stage relative to the number of methods for each theme. For example, $91 \%$ of all process redesign methods offer at least one activity in the Diagnose stage of the S-A framework. From Table 2 we can clearly see that process redesign methods are centered around the actual act of redesigning business processes, including activities that belong to the stages Diagnose, Redesign, and Reconstruct. In particular, all process redesign methods include at least one activity that belong to the stages of Redesign and Reconstruct. In comparison, $4 \%$ and $3 \%$ of the process reengineering and process improvement methods, respectively, do not offer any activity for the Redesign stage. Similarly, approximately $15 \%$ of all reengineering and improvement methods do not guide how to reconstruct a business process, which is not the case with the redesign methods. According to Table 2, reengineering and improvement methods place more focus on how to set up and evaluate an initiative that incrementally and radically changes a business process, but does not provide guidance on how to actually do that.

Only $36 \%$ of all redesign methods offer activities organizations can use to guide them on how to evaluate the performance of their redesigned business processes. However, this is not the case with the reengineering and improvement methods, where $67 \%$ and $79 \%$ can be used also for evaluating the reengineered and improved processes, respectively. Strategic activities concerned with the Envision stage are mostly offered by process reengineering methods, compared to redesign methods which offer the least strategic activities that will guide the redesign efforts. Most methods offer activities 
Table 3. Extended Stage-Activity framework for incremental and radical process change, adapted from [2]

\begin{tabular}{|c|c|c|}
\hline & & \\
\hline 1. Envision & 3. Diagnose & 5. Reconstruct \\
\hline Establish management commitment and vision* & Document existing process* & Reorganize* \\
\hline Understand business context & Verify existing process & Communicate process changes \\
\hline Identify key business goals & Conduct as-is process model simulation & Analyze implementaiton problems \\
\hline Identify comparative companies & Analyze existing process* & Draw up implementation schedule \\
\hline Analyze competitor's process & Assess process knowledge intensity & Identify potential employee resistance \\
\hline Develop organizational model & Analyze process environment & Implement cultural change program \\
\hline Realize need for change & Assess process maturity & Handover process accountability to process owner \\
\hline Analyze change dynamics & Benchmark process from within company & Implement IS* \\
\hline Restructure organization to support improvement & Benchmark process from competitors & Prototype to-be process \\
\hline project & Use process mining techniques & Integrate processes \\
\hline Evaluate existing culture & Perform goal analysis & Synthesize the new human resource infrastructure \\
\hline Obtain approval and resources & Identify change opportunities & Train users* \\
\hline Discover re-engineering opportunities* & & Process cut-over* \\
\hline Analyze problem situation & 4. Redesign & Analyze potential impact for other processes \\
\hline Derive critical success factors & Define and analyze new process concepts* & \\
\hline Identify IT levers* & Brainstorm process design ideas & 6. Evaluate \\
\hline Identify non-IT related levers & Adopt the clean sheet of paper approach & Evaluate process performance* \\
\hline Select process* & Identify new capabilities through emerging & Make process refinements \\
\hline Identify process stakeholders & technologies & Report key process change outcomes \\
\hline Align process change with corporate strategy & Identify necessary organizational changes & Link to continuous improvement programs \\
\hline Identify process boundaries & $\begin{array}{l}\text { Collect improvement ideas from stakeholders } \\
\text { Evaluate alternatives }\end{array}$ & $\begin{array}{l}\text { Monitor external environment for future needs to } \\
\text { change }\end{array}$ \\
\hline & Define improvement strategy & Check for future needs to change \\
\hline 2. Initiate & Create improvement plan & Assess and adjust improvement method \\
\hline Inform stakeholders* & Prototype and detailed design of a new process* & Initiate new reengineering project \\
\hline Define ownership & Compare as-is and to-be process & Analyze roles and reward system \\
\hline Gain staff commitment & Derive necessary changes & Recognize improvement participation \\
\hline Organize reengineering teams* & Solicit feedback & \\
\hline Conduct project planning* & Estimate required resources and organizational & \\
\hline Select software, tools and methods & change needed & \\
\hline Conduct methodological training & Conduct to-be process model simulation & \\
\hline Determine external process customer requirements* & Standardize to-be process & \\
\hline Identify process customers and stakeholders & Design human resource structure* & \\
\hline Set performance goals* & Analyze and design IS* & \\
\hline Envision new process & Develop best practices & \\
\hline Set improvement goals & Outline key measurement variables & \\
\hline Conduct cost/benefit analysis & & \\
\hline
\end{tabular}

from the Diagnose stage, which indicates an emphasis on the modeling and analysis of business processes. This indicates the tendency to start with an existing process rather than focusing on a clean slate approach, as proposed by [7].

The activity mapping also enabled us to identify activities beyond the ones mentioned in the S-A framework by [2]. The S-A framework includes 21 activities across all six stages. We identified 68 additional activities that extend the framework. From these, 16 are activities that have been proposed to conduct during the Envision stage, 8 are in the Initiate stage, and 10 were identified in the Diagnose stage. The Redesign stage is extended by 16 additional activities, the Reconstruct stage by 10 , and the Evaluate stage by 8 activities. The extended list of activities for the six stages can be seen in Table 3. The activities with an asterisk occur in the original S-A framework as found in [2].

From Table 3 we can observe that, many of the additional activities (e.g. 'Communicate process changes' from Reconstruct, 'Collect improvement ideas from stakeholder from Redesign', etc.) emphasize communication with the staff throughout the process change initiative, in contrast to the original S-A framework where staff communication was not present. We also found activities concerned with concepts and techniques that were not yet established at the time the S-A framework was introduced. Examples of such activities are 'Assess process maturity' from the Diagnose stage and 'Conduct as-is and to-be process model simulation' from the Diagnose and Redesign stages, respectively. Several activities have been recommended by other methods that recognize the need to deal with potential resistance towards the process change. Activities such as 'Evaluate existing culture' (Envision), 'Implement cultural change program' (Reconstruct) and 'Identify potential employee resistance' (Reconstruct) have been conducted by organizations in order to ensure a successful process change. This seems especially important when a clean slate approach is adopted, which is an activity from the Redesign stage sometimes followed by organizations when radically changing their business process.

We found that many methods include activities which are concerned with the understanding of the business context, identifying of key business goals and realizing the need for change, all done during the Envision stage. These types of activities exceed 


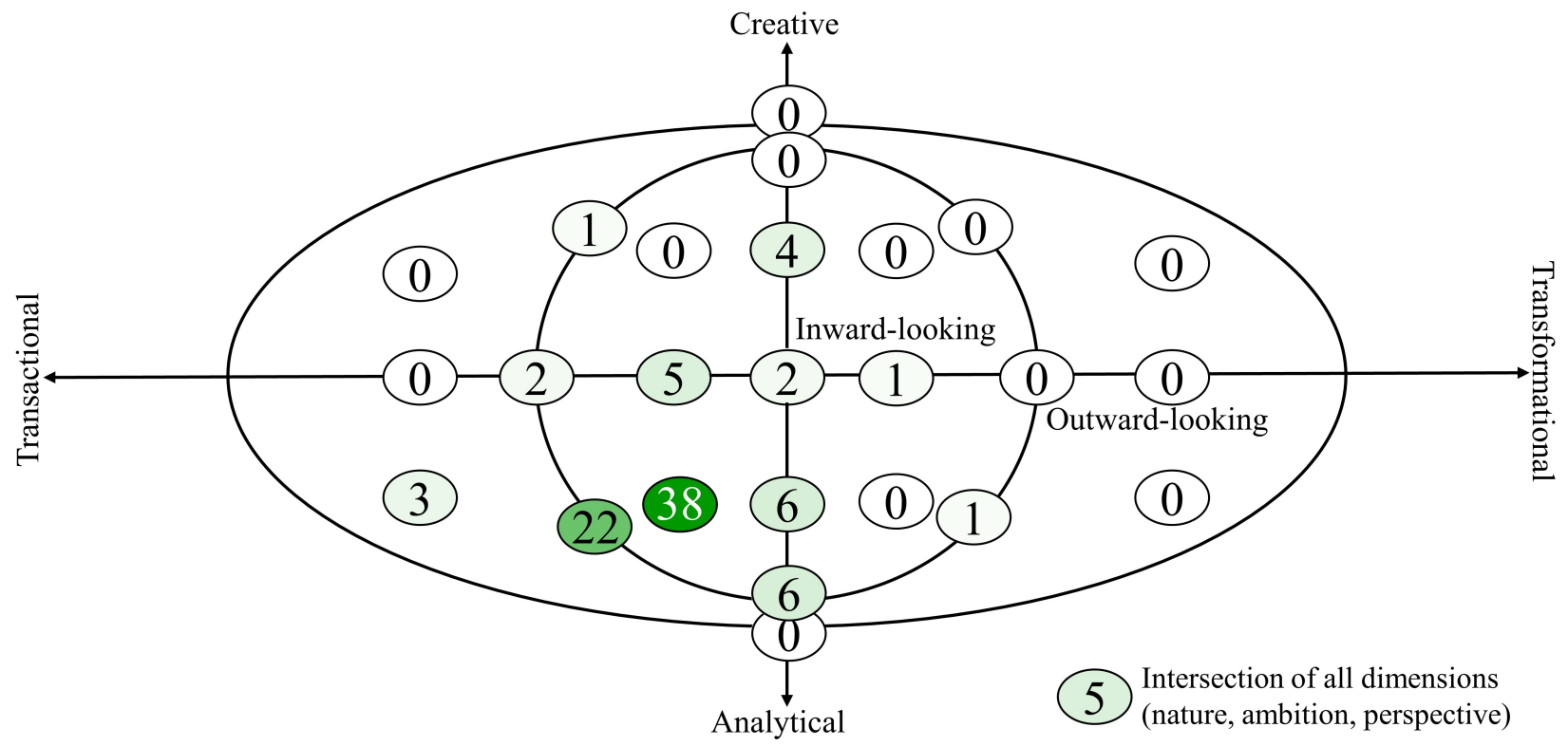

Figure 2. A spectrum of process change methods in the redesign orbit, adapted from [1]

the scope of the 'Set performance goals' activity from the S-A framework, since performance goals are metrics derived from objectives. Additionally, many activities we identified are regarding the people involved in the process change program. During the Initiate stage it is recommended to 'Define ownership', 'Gain staff commitment' and 'Conduct methodological training'. Whereas during the Evaluate stage other methods include activities that recognize the acknowledgment of people that were involved during the process change initiative, such as the activities 'Analyze roles and reward system' and 'Recognize improvement participation'. Finally, we observed that, besides evaluating the process change success, some organizations also 'Assess and adjust the improvement method' they follow (Evaluate).

As last step of our analysis, we positioned the methods we gathered in the spectrum of the redesign orbit as introduced by [1]. We did this by identifying the nature, perspective and ambition of all methods. We only did this for 96 methods, because it was not possible to identify the nature of two methods. The redesign orbit can be seen in Figure 2. Our results show that, 76 methods are categorized as analytical (e.g. $[27,28,29]), 5$ as creative (e.g. [12, 30, 31]) and 10 are in the intersection of both, analytical and creative (e.g. $[32,33])$. This means that, 76 methods include activities that guide organizations to analyze and redesign their business processes based only on process data, whereas only 5 methods encourage employees to bring up ideas on how a process should be redesigned. The 10 methods that are positioned on the intersection of both are ones that offer both types of activities.

In terms of the ambition, we found that 71 methods lead to transactional process change (e.g. [34, 35, $36]$ ), while only 2 are methods that would enable transformational change $[32,37]$. On the other hand, we found 18 methods organizations could use that would lead to both transactional and transformational process change (e.g. $[29,33,38]$ ). These are positioned on the intersection of both ends of the axis. In the perspective dimension, the categorization was also unequally distributed. 56 methods are inward-looking (e.g. [32, 33, 35]), which means they only consider company data to change their business processes. We found 3 methods that are only outward-looking [27, 39, 40]. These do not recognize internal problems with the process, but rather listen to their customers and improve their processes accordingly. Lastly, 32 methods are inward- as well as outward-looking (e.g. [17, 28, 29]). These include activities that recommend organizations to consider both customers and company data in order to come up with ideas on how to change the processes.

When we take into consideration all three dimensions (nature, ambition, and perspective), we can observe that there is an increased focus on specific areas of the redesign orbit. Namely, 38 methods are categorized as being analytical, transactional, and inward-looking (e.g. [18, 35, 36, 41, 42]). Hence, these are methods that would likely only lead to incremental process improvement. On the other hand, 22 methods have the same characteristics as the 
38 ones, however in addition they also include the outward-looking perspective (e.g. [11, 17, 15, 43, 44]). Thus, these methods seem to recommend to also listen to the customer voice when undertaking process change. Due to the two-dimensionality of the redesign orbit, we were not able to place 5 methods within its borders. This means that, these methods include activities that recommend to be all, analytical, creative, inward-looking, outward-looking, transactional and transformational (e.g. [19, 34]).

\subsection{Discussion and Implications of Findings}

Figure 1 shows that, up until 2017, process change methods have been continuously introduced or refined, which indicates the relevance of the topic. From Table 2 we can see that, clearly, the theme that mostly differs is process redesign. All process redesign methods we collected focus on the actual reconstructing and redesigning of business processes. However, almost $40 \%$ seem to neglect strategically-oriented activities that will ensure management commitment and strategic alignment. This is not the case with the process reengineering and improvement methods, where the majority of methods include at least one activity in most of the stages from the S-A framework.

Therefore, we might question whether it makes sense to differentiate between the different themes. Our findings suggest that, regardless of the theme, most methods could be used for incrementally or radically changing a process. We were not able to see any difference in the ambition of the differently-themed methods. As such, we could argue that the three themes of process change, namely redesign, reengineering and improvement, could in fact be used interchangeably. This interchangeable use of themes can also be observed in literature. For instance, in [45] manufacturing processes are redesigned through reengineering and benchmarking, or according to [46] process reengineering is concerned with the fundamental rethinking and radical redesign of business processes to obtain both dramatic and sustaining improvements.

The redesign orbit might offer a better basis for discussing the differences of the methods we gathered. The majority of methods have been used for incrementally improving business processes. These also rely solely on analytical methods and as such use process data for identifying process weaknesses. Studies have shown that this is one of the key pitfalls that often leads to unsuccessful BPM initiatives. Namely, an organization that constantly focuses on finding process weaknesses by only considering process data often misses out on innovativeness [47]. Considering customer requirements, instead, might lead to more radical outcome. However, a method that is only outward-looking, but does not use creative methods, such as brainstorming, to come up with improvement ideas is also one that rather leads to incremental improvement. Indeed, there seem to exist methods that would assist organizations in their incremental process change initiatives. There is a clear lack of research on creative, outward-looking and transformational methods which would guide organizations to radically improve their business processes.

Recently, few approaches have been introduced that could lead to radical process change. For instance, NESTT is an approach for rapid process redesign that starts the initiative by first describing the ambition for the future process [48]. Similarly, the process model canvas allows organizations to reason about the value proposition, and starts from the wow! factor behind a business process [1]. Learning from the future and ensuring the sense of excitement might indeed lead to a breakthrough innovation, because for both organizations should abandon their traditional line of thinking about their existing processes. We did not observe this type of radical thinking in any of the methods we gathered. [49] argues that, a company's focus on increasing productivity obstructs its flexibility and ability to innovate. While incremental process change addresses the needs of existing customers, designing and introducing services for new markets and new customer sets are often organizationally disruptive and require significant departure from existing activities [50]. Such departure often requires new knowledge and newly developed skills [50].

We have noticed that several of the recent start-up success stories appear to be highly process-centered (e.g. UBER). However, they do not seem to rely on classic BPM methods. Possible explanation might be due to the strict nature of methods, they imply conducting activities in a predefined order. Such strict execution of activities might hinder innovation, which is typically result of a creative process. Second, incremental process change might not be enough for organizations to keep up with their competitors. Since most existing process change methods do not seem to assist radical process change, future research is necessary to complete this gap.

\section{Conclusion and Limitations}

The aim of this study was to investigate the differences between existing process change methods. We found 98 such methods by means of a systematic 
literature review. We developed a process change framework which includes an extended list of activities categorized in six stages. We found that the majority of process change methods are analytical and transactional, while one fourth also take the outward-looking perspective, whilst pursuing incremental process change. Our findings could be used by practitioners for their future process change initiatives. However, we also point towards the necessity of exploring how to assist organizations for their radical process change initiatives.

Our study is also subject of limitations. First of all, we only used ProQuest as a digital library to search for studies on process change methods. Although we found a very large number of methods, this does not mean the list is exhaustive. Second, the list of additional activities we found differ in their level of granularity. This is an aspect that needs further research. Third, the methods might differ because of the different contexts they have been used in, and the different objectives that were pursued. This is an important aspect that must be considered, however it goes beyond the purpose of this study.

\section{References}

[1] M. Dumas, M. La Rosa, J. Mendling, and H. A. Reijers, Fundamentals of Business Process Management. Springer, second ed., 2018.

[2] W. Kettinger, J. Teng, and S. Guha, "Business Process Change: a Study of Methodologies, Techniques, and Tools," MIS Quarterly, pp. 55-80, 1997.

[3] T. Davenport, Process Innovation: Reengineering Work Through Information Technology. Harvard Business School Press, 1993.

[4] M. Zairi, "Business process management: a boundaryless approach to modern competitiveness,' Business Process Management Journal, vol. 3, no. 1, pp. 64-80, 1997.

[5] W. J. Kettinger and V. Grover, "Special section: toward a theory of business process change management," Journal of Management Information Systems, pp. 9-30, 1995.

[6] R. N. Kiraka and K. Manning, "Managing organisations through a process-based perspective: its challenges and benefits," Knowledge and Process Management, vol. 12, no. 4, pp. 288-298, 2005

[7] M. Hammer and J. Champy, Reengineering the Corporation: A Manifesto for Business Revolution. HarperBusiness.

[8] P. Checkland, Systems thinking, systems practice. CUMINCAD, 1981.

[9] R. Maull and S. Childe, "Business process re-engineering: an example from the banking sector," International Journal of Service Industry Management, vol. 5, no. 3, pp. 26-34, 1994.

[10] $\mathrm{L}$. $\mathrm{Wu}$, "A model for implementing bpr based on strategic perspectives: an empirical study," Information \& Management, vol. 39, no. 4, pp. 313-324, 2002.
[11] D. J. Paper, J. A. Rodger, and P. C. Pendharkar, "A bpr case study at honeywell," Business Process Management Journal, vol. 7, no. 2, pp. 85-99, 2001.

[12] N. Shin and D. F. Jemella, "Business process reengineering and performance improvement: The case of chase manhattan bank," Business Process Management Journal, vol. 8, no. 4, pp. 351-363, 2002.

[13] M. d. Hengst and G.-J. D. Vreede, "Collaborative business engineering: a decade of lessons from the field," Journal of Management Information Systems, vol. 20, no. 4, pp. 85-114, 2004.

[14] M. Meadows and Y. Merali, "Process improvement with vision: A financial services case study," Systemic Practice and Action Research, vol. 16, no. 3, pp. 171-195, 2003.

[15] T. Bortolotti and P. Romano, "lean first, then automate: a framework for process improvement in pure service companies. a case study," Production Planning \& Control, vol. 23, no. 7, pp. 513-522, 2012.

[16] A. R. Tenner, "Quality management beyond manufacturing," Research-Technology Management, vol. 34, no. 5, pp. 27-32, 1991.

[17] F. Martin, "A performance technologist's approach to process performance improvement," Performance Improvement, vol. 47, no. 2, pp. 30-40, 2008

[18] T. R. Rohleder and E. A. Silver, "A tutorial on business process improvement," Journal of Operations Management, vol. 15, no. 2, pp. 139-154, 1997.

[19] B. Povey, "The development of a best practice business process improvement methodology," Benchmarking for Quality Management \& Technology, vol. 5, no. 1, pp. 27-44, 1998.

[20] D. Brian Harrison and M. D. Pratt, "A methodology for reengineering businesses," Planning Review, vol. 21, no. 2, pp. 6-11, 1993.

[21] H. J. Harrington, "Continuous versus breakthrough improvement: finding the right answer," Business Process Re-engineering \& Management Journal, vol. 1, no. 3, pp. 31-49, 1995 .

[22] T. H. Davenport and J. E. Short, "The new industrial engineering: Information technology and business process redesign," Sloan Management Review, vol. 31, no. 4, pp. 11-27, 1990 .

[23] J. T. Teng, V. Grover, and K. D. Fiedler, "Re-designing business processes using information technology," Long Range Planning, vol. 27, no. 1, pp. 95-106, 1994.

[24] S. L. Mansar and H. A. Reijers, "Best practices in business process redesign: validation of a redesign framework," Computers in industry, vol. 56, no. 5, pp. 457-471, 2005.

[25] S. Brinkkemper, "Method engineering: engineering of information systems development methods and tools," Information and software technology, vol. 38, no. 4, pp. 275-280, 1996.

[26] B. Kitchenham, O. Pearl Brereton, D. Budgen, M. Turner, J. Bailey, and S. Linkman, "Systematic literature reviews in software engineering-a systematic literature review," Information and software technology, vol. 51, no. 1, pp. 7-15, 2009.

[27] M. Attaran, "Why does reengineering fail? a practical guide for successful implementation," Journal of management development, vol. 19, no. 9, pp. 794-801, 2000. 
[28] S. Adesola and T. Baines, "Developing and evaluating a methodology for business process improvement," Business Process Management Journal, vol. 11, no. 1, pp. 37-46, 2005.

[29] J. Sarkis, A. Presley, and D. Liles, "The strategic evaluation of candidate business process reengineering projects," International Journal of Production Economics, vol. 50, no. 2-3, pp. 261-274, 1997.

[30] M. Alavi and Y. Yoo, "Productivity gains of bpr achieving success where others have failed," Information System Management, vol. 12, no. 4, pp. 43-48, 1995.

[31] A. Lockamy III and W. I. Smith, "A strategic alignment approach for effective business process reengineering: linking strategy, processes and customers for competitive advantage," International journal of production economics, vol. 50, no. 2-3, pp. 141-153, 1997.

[32] J. Teng, V. Grover, and K. Fiedler, "Developing strategic perspectives on business process reengineering: from process reconfiguration to organizational change," Omega, vol. 24, no. 3, pp. 271-294, 1996.

[33] V. Grover and M. K. Malhotra, "Business process reengineering: A tutorial on the concept, evolution, method, technology and application," Journal of operations management, vol. 15, no. 3, pp. 193-213, 1997.

[34] D. Paper, "The value of creativity in business process re-engineering," Business Process Management Journal, vol. 3, no. 3, pp. 218-231, 1997.

[35] N. Damij, T. Damij, J. Grad, and F. Jelenc, "A methodology for business process improvement and is development," Information and software technology, vol. 50, no. 11, pp. 1127-1141, 2008.

[36] C. R. Haddad, D. H. F. Ayala, M. Uriona Maldonado, F. A. Forcellini, and Á. G. R. Lezana, "Process improvement for professionalizing non-profit organizations: Bpm approach," Business Process Management Journal, vol. 22, no. 3, pp. 634-658, 2016.

[37] A. Ascari, M. Rock, and S. Dutta, "Reengineering and organizational change: lessons from a comparative analysis of company experiences," European Management Journal, vol. 13, no. 1, pp. 1-30, 1995.

[38] A. Margherita and C. Petti, "Ict-enabled and process-based change: an integrative roadmap," Business Process Management Journal, vol. 16, no. 3, pp. 473-491, 2010.

[39] B. Prasad, "A structured approach to product and process optimization for manufacturing and service industries," International Journal of Quality \& Reliability Management, vol. 12, no. 9, pp. 123-138, 1995.

[40] T. R. Furey, “A six-step guide to process reengineering," Planning Review, vol. 21, no. 2, pp. 20-23, 1993.

[41] R. Archer and P. Bowker, "Bpr consulting: an evaluation of the methods employed," Business Process Re-engineering \& Management Journal, vol. 1, no. 2, pp. 28-46, 1995.

[42] M. Vakola and Y. Rezgui, "Critique of existing business process re-engineering methodologies: The development and implementation of a new methodology," Business process Management journal, vol. 6, no. 3, pp. 238-250, 2000.
[43] B. Fitzgerald and C. Murphy, "Business process re-engineering: Putting theory into practice," INFOR: Information Systems and Operational Research, vol. 34, no. 1, pp. 3-14, 1996.

[44] Z. Khan, R. K. Bali, and N. Wickramasinghe, "Developing a bpi framework and pam for smes," Industrial Management \& Data Systems, vol. 107, no. 3, pp. 345-360, 2007.

[45] W. Kam-Chuen Yung, "A stepped composite methodology to redesign manufacturing processes through re-engineering and benchmarking," International Journal of Operations \& Production Management, vol. 17, no. 4, pp. 375-388, 1997.

[46] A. Gunasekaran and B. Nath, "The role of information technology in business process reengineering," International journal of production economics, vol. 50, no. 2-3, pp. 91-104, 1997.

[47] M. Malinova and J. Mendling, "Identifying dos and donts using the integrated business process management framework," Business Process Management Journal, 2018.

[48] M. Rosemann, "The nestt: Rapid process redesign at queensland university of technology," in Business Process Management Cases, pp. 169-185, Springer, 2018.

[49] J. M. Utterback and W. J. Abernathy, "A dynamic model of process and product innovation," Omega, vol. 3, no. 6, pp. 639-656, 1975.

[50] M. J. Benner and M. L. Tushman, "Exploitation, exploration, and process management: The productivity dilemma revisited," Academy of management review, vol. 28, no. 2, pp. 238-256, 2003. 